\title{
Twenty-four-hour ambulatory blood pressure monitoring detects a high prevalence of hypertension late after coarctation repair in patients with hypoplastic arches
}

\author{
Melissa G. Y. Lee, BMedSc, ${ }^{a}$ Remi Kowalski, MBBS, ${ }^{b}$ John C. Galati, PhD, ${ }^{c}$ \\ Michael M. H. Cheung, MBChB, ${ }^{\mathrm{b}}$ Bryn Jones, MBBS, ${ }^{\mathrm{b}}$ Jane Koleff, DipMedLabSc, ${ }^{\mathrm{b}}$ and \\ Yves d'Udekem, MD, $\mathrm{PhD}^{\mathrm{a}}$
}

\begin{abstract}
Objectives: To determine by 24-hour blood pressure monitoring the risk of hypertension late after coarctation repair in patients with arch hypoplasia.
\end{abstract}

\begin{abstract}
Methods: Sixty-two of 116 consecutive patients (age, $\geq 10$ years) who had coarctation repair and were quoted subjectively by the surgeon or the cardiologist to have arch hypoplasia at the time of the repair underwent a transthoracic echocardiogram and 24-hour blood pressure monitoring. Median age at repair was 11 days (range, 6-48 days). Mean preoperative $\mathrm{z}$ score of the proximal transverse arch was $-2.43 \pm 0.46$. Eight patients had a repair via sternotomy ( 6 end-to-side anastomoses, 2 patch repairs) and 54 had a conventional repair via thoracotomy.

Results: After a follow-up of $18 \pm 5$ years, $27 \%$ of the patients (17/62) had resting hypertension and $60 \%$ (37/ 62 ) had abnormal ambulatory blood pressure. Sensitivity of high resting blood pressure in detecting an abnormal 24-hour ambulatory blood pressure was $41 \%$. Twenty patients had arch obstruction at last follow-up. Eighteen of them $(90 \%)$ had abnormal ambulatory blood pressure. None of the patients operated on with end-to-side repair via sternotomy had reobstruction compared with 33\% (18/54) of those repaired via thoracotomy.
\end{abstract}

Conclusions: Patients with a hypoplastic arch operated via thoracotomy have an alarming prevalence of hypertension. Regular follow-up with 24-hour ambulatory blood pressure monitoring is warranted, especially in patients who have had a smaller aortic arch at the time of the initial operation. (J Thorac Cardiovasc Surg 2012;144:1110-8)

Patients who underwent a coarctation repair are at risk of developing hypertension at a young age, but the mechanism leading to hypertension and its true prevalence are still unclear. The vast majority of studies reporting prevalence of hypertension have been retrospective reviews reporting the prevalence of reported cases of hypertension diagnosed on the basis of casual blood pressure measurement in outpatient clinics. ${ }^{1-3}$ Accordingly, the prevalence of hypertension has been quoted to vary between $17 \%$ and $75 \%{ }^{1-6}$ In historical series, the development of hypertension after coarctation repair has been shown to

From the Departments of Cardiac Surgery ${ }^{\mathrm{a}}$ and Cardiology, ${ }^{\mathrm{b}}$ The Royal Children's Hospital, Department of Paediatrics, University of Melbourne, and the Clinical Epidemiology and Biostatistics Unit, ${ }^{c}$ Murdoch Children's Research Institute, Melbourne, Australia.

This research project was supported by the Victorian Government's Operational Infrastructure Support Program.

Disclosures: Yves d'Udekem is a Career Development Fellow of The National Heart Foundation of Australia (CR 10M 5339). All other authors have nothing to disclose with regard to commercial support.

Read at the 92nd Annual Meeting of The American Association for Thoracic Surgery, San Francisco, California, April 28-May 2, 2012.

Received for publication April 24, 2012; revisions received July 10, 2012; accepted for publication Aug 1, 2012; available ahead of print Sept 13, 2012.

Address for reprints: Yves d'Udekem, MD, PhD, Department of Cardiac Surgery, Royal Children's Hospital, Flemington Rd, Parkville, Melbourne 3052, Victoria, Australia (E-mail: yves.dudekem@ rch.org.au). 0022-5223/\$36.00

Crown Copyright (C) 2012 Published by Elsevier Inc. on behalf of The American Association for Thoracic Surgery

http://dx.doi.org/10.1016/j.jtcvs.2012.08.013 lead to premature death by complications related to accelerated atherosclerosis. ${ }^{3}$ It has now been demonstrated that the gold standard examination for detecting hypertension is 24-hour blood pressure monitoring, because it is more closely related to end-organ damage than screening with casual blood pressure monitoring. ${ }^{7,8}$ After coarctation repair, it has been demonstrated that screening with only casual resting blood pressure measurements would leave a third of patients with hypertension undetected. ${ }^{4}$

One of the leading factors resulting in hypertension is the presence of residual arch obstruction. ${ }^{6}$ For decades, it was believed that smaller aortic arches would grow once normal antegrade flow was restored in the arch after coarctation repair. ${ }^{9-11}$ We recently demonstrated that the growth of the proximal transverse arch was unpredictable after coarctation repair, and we feared that a large proportion of patients with hypoplastic arches undergoing coarctation repair may become hypertensive. ${ }^{12} \mathrm{We}$ investigated this population of patients with hypoplastic arches using 24-hour blood pressure monitoring to determine their prevalence of hypertension late after coarctation repair.

\section{METHODS \\ Study Population}

The design of the study was approved by the Royal Children's Hospital Human Research and Ethics Committee. The hospital database was screened to identify the patients who had survived repair of coarctation 


\section{Abbreviation and Acronym \\ $\mathrm{CI}=$ confidence interval}

of the aorta at the Royal Children's Hospital between 1984 and 2004, who were quoted as having a hypoplastic arch at the time of the repair, and who were currently living in the state of Victoria. A patient's arch was defined as hypoplastic if the echocardiogram report, the cardiologist's report, or the surgical notes labeled it as hypoplastic. Exclusion criteria were univentricular physiology, intellectual disability, and age $<10$ years. Of the 116 identified patients, $25(22 \%)$ could not be contacted. Of the 81 patients who replied, 62 (36 males and 26 females) agreed to participate. The files and all preoperative examinations of the patients were reviewed. The patients who took part in the study were comparable with the patients who did not reply to the letter, in terms of age, gender ratio, and age at time of repair.

Surgical repair of coarctation and hypoplastic arch had been performed at a median age of 11 days (range, 6-48 days), and 58 patients (94\%) had undergone surgery during the first year of life. Characteristics of the patients are displayed in Table 1. The list of surgical procedures of the aortic arch (Figure 1) and concomitant cardiac procedures are listed in Table 2.

Twenty patients $(32 \%)$ had undergone an arch reintervention after a mean of $3.1 \pm 5.1$ years following their initial surgical repair for coarctation. Fourteen patients ( $70 \%$ ) had 1 balloon angioplasty procedure, 2 patients $(10 \%)$ had 2 balloon angioplasty procedures, 2 patients $(10 \%)$ had a patch repair, 1 patient $(5 \%)$ had both a balloon angioplasty and a patch repair, and 1 patient $(5 \%)$ had an endovascular stent insertion into the aortic arch.

Eight patients needed the following nonarch-related cardiac reinterventions: 1 patient had an arterial switch operation, 1 patient had a plication of the diaphragm and a ventricular septal defect closure, 1 patient had an atrioventricular septal defect closure, 1 patient had a ventricular septal defect closure and an aortic valvotomy, 1 patient had a left ventricular assist device cannulation, 1 patient had an aortopulmonary window closure, 1 patient had a pulmonary artery band, and 1 patient had a ventricular septal defect closure.

The mean age at follow-up was $18 \pm 5$ years. The mean duration of follow-up was $18 \pm 5$ years.

\section{Study Protocol}

Written informed consent was obtained from each patient or their parents if $<18$ years of age. All patients underwent transthoracic echocardiography and supine resting blood pressure in both the left and right arms and in the left leg.

All 62 patients underwent 24-hour ambulatory blood pressure monitoring. Patients were advised to continue going to school or work, but to avoid physical education classes or participation in sports.

\section{Echocardiography}

Echocardiographic examinations were performed used a standard ultrasound machine (Vivid 7; GE Healthcare, Bedford, UK) with patients in the left lateral decubitus position. Measurements of aortic diameter were made in 5 different regions by an echocardiography technician blinded to patient history. The 5 aortic regions measured were distal ascending aorta, proximal transverse arch (defined as the segment of aorta between the brachiocephalic and left common carotid arteries), distal transverse arch (defined as the segment between the left common carotid and left subclavian arteries), aortic isthmus, and descending aorta. Aortic diameters were converted to $\mathrm{z}$ scores using a separate reference population from the Children's Hospital of Michigan in Detroit. ${ }^{13}$ An aortic region with a $\mathrm{z}$ score diameter $<-2.0$ was considered to be hypoplastic.
Reobstruction of the arch was defined as a peak gradient $>25 \mathrm{~mm} \mathrm{Hg}$ across the repair site on echocardiography, or an upper limb-to-lower limb blood pressure gradient $>20 \mathrm{~mm} \mathrm{Hg}$. Left ventricular mass was calculated from 2-dimensional guided M-mode measurements of the left ventricle using the recommended formula of the American Society of Echocardiography. ${ }^{14}$ Left ventricular mass index was calculated by dividing left ventricular mass by height ${ }^{2.7}$ in meters to minimize the effects of age, gender, ethnicity, and body mass index..$^{15,16}$ Left ventricular hypertrophy in children and adolescents was defined as a left ventricular mass index $>95$ th percentile $\left(38.6 \mathrm{~g} / \mathrm{m}^{2.7}\right)$ for healthy children and adolescents. ${ }^{15}$ In adults, it was defined as a left ventricular mass index $>51 \mathrm{~g} / \mathrm{m}^{2.7} .{ }^{16}$

\section{Resting Blood Pressure}

Measurements of casual resting blood pressure were made by an automatic oscillometric method (Dinamap PRO 100; GE Healthcare) after at least 5 minutes of rest in the supine position, with appropriate-size cuffs that covered at least two thirds of the upper arm and thigh. Measurements were taken 3 times in both the left and right arms and in the left leg, and the mean of the 3 readings was used as the resting blood pressure in that limb. Resting hypertension for children and adolescents was defined as a systolic and/or diastolic blood pressure $>95$ th percentile for age and height; and prehypertension was defined as between the 90th and 95th percentile or if blood pressure was $>120 / 80 \mathrm{~mm} \mathrm{Hg} .{ }^{17} \mathrm{In}$ adults, resting hypertension was defined as a systolic blood pressure $>140 \mathrm{~mm} \mathrm{Hg}$ and/or a diastolic blood pressure $>90 \mathrm{~mm} \mathrm{Hg}$; prehypertension was defined as systolic blood pressure between $120 \mathrm{~mm} \mathrm{Hg}$ and $139 \mathrm{~mm} \mathrm{Hg}$ and/or diastolic blood pressure between $80 \mathrm{~mm} \mathrm{Hg}$ and $89 \mathrm{~mm} \mathrm{Hg}{ }^{18}$

\section{Ambulatory Blood Pressure Monitoring}

A validated oscillometric device (Oscar 2; SunTech Medical, SunTech Medical Group Limited, Oxfordshire, UK) was used on the right arm of all patients using an appropriate-size cuff. Patients were asked approximately what time they would go to bed that night (asleep time) and what time they would wake up the next morning (awake time) for appropriate programming of the monitor. Blood pressure measurements were performed automatically every 30 minutes during awake time and every 60 minutes during asleep time. Abnormal blood pressure on ambulatory blood pressure monitoring was defined in children as systolic blood pressure load $>25 \%$, mean ambulatory systolic blood pressure $\geq 95$ th percentile for a separate reference population, and/or clinical blood pressure at $\geq 95$ th percentile. ${ }^{8}$ In adults, ambulatory blood pressure was defined as abnormal when the mean 24 -hour blood pressure $\geq 135 / 85 \mathrm{~mm} \mathrm{Hg}{ }^{19}$

\section{Statistical Analysis}

All data were exported to and analyzed using STATA version 10.1 (Stata Corporation, College Station, Tex). Data were expressed as mean \pm standard deviation or median (interquartile range). All pre- and perioperative data, and parameters were extracted from the echocardiographic examination performed on the day of the study. Nonpaired Student $t$ test and Pearson $\chi^{2}$ test (or Fisher exact test, when appropriate) were used to analyze intergroup comparisons between patients with and without resting hypertension and abnormal ambulatory blood pressure. Logistic regression was used to assess the association of left ventricular hypertrophy with abnormal ambulatory blood pressure, and to assess the univariate association of resting hypertension and abnormal ambulatory blood pressure with clinical and echocardiographic variables. Because of the small number of outcomes, the large variety in surgical techniques, and the small number of patients for which all covariates were available, we felt that it was not feasible to perform multivariate analyses for these associations. 
TABLE 1. Patient characteristics

\begin{tabular}{lc}
\multicolumn{1}{c}{ Characteristic } & $\mathbf{n}(\%)$ \\
\hline General data & \\
No. of patients & 62 \\
Male & $36(58 \%)$ \\
Female & $26(42 \%)$ \\
Median birth weight, kg (range) & $3.3(2.76-3.70)$ \\
Median age at surgery, d (range) & $11(6-48)$ \\
Demographics & \\
Median age at time of study, y (range) & $17(14-22)$ \\
Median height at study, cm (range) & $167.3(154.5-172.0)$ \\
Median weight at study, kg (range) & $64.1(47.8-76.5)$ \\
Cardiac anomalies & \\
Ventricular septal defect & $38(61 \%)$ \\
Bicuspid aortic valve & $27(44 \%)$ \\
Atrial septal defect & $13(21 \%)$ \\
Patent foramen ovale & $13(21 \%)$ \\
Borderline small left ventricle & $5(8 \%)$ \\
Transposition of the great arteries & $5(8 \%)$ \\
Left ventricular outflow obstruction & $4(7 \%)$ \\
Left superior vena cava & $4(7 \%)$ \\
Atrioventricular septal defect & $3(5 \%)$ \\
Anomalous right subclavian artery & $3(5 \%)$ \\
Double-outlet right ventricle & $2(3 \%)$ \\
Taussig-Bing anomaly & $2(3 \%)$ \\
Mitral valve stenosis or incompetence & $2(3 \%)$ \\
Bovine aortic arch & $2(3 \%)$ \\
Partial anomalous pulmonary venous drainage & $1(2 \%)$ \\
Aortopulmonary window & $1(2 \%)$ \\
Ebstein anomaly & $1(2 \%)$ \\
Dextrocardia & $1(2 \%)$ \\
Noncardiac anomalies & \\
Down syndrome & $1(2 \%)$ \\
Noonan syndrome & $1(2 \%)$ \\
Turner syndrome & $1(2 \%)$ \\
William syndrome & $1(2 \%)$ \\
\hline & \\
\hline & \\
\hline
\end{tabular}

\section{RESULTS}

\section{Preoperative Aortic Arch Dimensions}

Preoperative echocardiographic examinations were available in 38 of the 62 participants $(61 \%)$. An accurate proximal arch diameter could not be obtained in 9 patients because of a common or close origin of the brachiocephalic and left common carotid arteries. Ten patients could not have their distal transverse arch diameter measured accurately. The mean presurgical proximal transverse arch $\mathrm{z}$ score (29 patients) and mean distal transverse arch z score (28 patients) were $-2.43 \pm 0.46$ and $-1.98 \pm 0.58$, respectively.

\section{Resting and 24-Hour Blood Pressure Measurements}

Seventeen of 62 patients $(27 \%)$ had resting hypertension whereas another 32 patients $(52 \%)$ had resting prehypertension. This left only 13 of 62 patients $(21 \%)$ with normal resting blood pressure. Thirty-seven of 62 patients $(60 \%)$

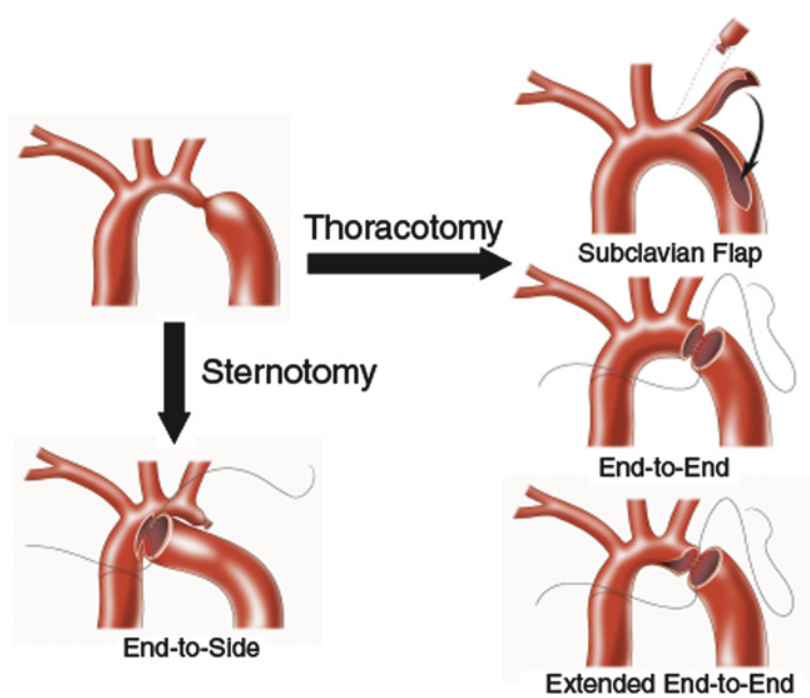

FIGURE 1. Surgical techniques for aortic arch repair.

had abnormal ambulatory blood pressure. Only 15 of 37 patients $(41 \%)$ with abnormal ambulatory blood pressure had resting hypertension. An increased resting blood pressure had a specificity of $92 \%(95 \%$ confidence interval [CI], 75-98) in detecting an increased 24-hour blood pressure, but had a poor sensitivity of $41 \%(95 \% \mathrm{CI}, 26-57)$.

Thirty-two of the 37 patients $(86 \%)$ with abnormal 24-hour blood pressure measurements were unaware of their hypertension. Four of the 6 patients receiving antihypertensive medication still had abnormal 24-hour blood pressure.

\section{Aortic Arch Dimensions and Reobstruction at the Time of the Study}

Reobstruction. Measurements of maximum flow velocity in the descending aorta on echocardiogram were obtained in 61 of 62 patients $(98 \%)$ ). Twenty of these 61 patients $(33 \%)$ had a peak gradient $>25 \mathrm{~mm} \mathrm{Hg}$ and were therefore defined to have arch reobstruction (Table 3). One third of the patients who underwent thoracotomy repair (18 of 54) had reobstruction whereas all 5 patients who underwent an end-to-side repair via sternotomy were free from reobstruction. Both patients operated on with a patch repair via sternotomy had arch reobstruction. Ninety percent of patients with arch reobstruction had abnormal ambulatory blood pressure. However, only 9 of 17 patients $(53 \%)$ with resting hypertension and 18 of 37 patients $(49 \%)$ with abnormal ambulatory blood pressure had arch reobstruction. Only 1 of the 20 patients (5\%) with arch reobstruction on echocardiography also had an upper limb-to-lower limb blood pressure gradient of more than $20 \mathrm{~mm} \mathrm{Hg}$, and had both resting hypertension and abnormal ambulatory blood pressure. The sensitivity of upper limbto-lower limb gradient to detect reobstruction on echocardiogram was 5\% (95\% CI, 0.9-24). 
TABLE 2. Operative data

\begin{tabular}{lc}
\hline \multicolumn{1}{c}{ Operative Data } & $\mathbf{n}(\boldsymbol{\%})$ \\
\hline Surgical era & \\
$1986-1989$ & $20(32 \%)$ \\
$1990-1999$ & $38(61 \%)$ \\
$2000-2003$ & $4(7 \%)$ \\
Arch repair technique & \\
Sternotomy & $8(13 \%)$ \\
End-to-side anastomosis & $6(75 \%)$ \\
Patch repair & $2(25 \%)$ \\
Thoracotomy & $54(87 \%)$ \\
End-to-end anastomosis & $4(7 \%)$ \\
Extended end-to-end anastomosis & $17(31 \%)$ \\
End-to-side anastomosis & $3(6 \%)$ \\
Subclavian flap repair & $27(50 \%)$ \\
Patch repair & $1(2 \%)$ \\
Miscellaneous arch repair & $2(4 \%)$ \\
Associated cardiac procedures & \\
Sternotomy & 8 \\
Ventricular septal defect closure & $5(63 \%)$ \\
Atrial septal defect closure & $2(25 \%)$ \\
Arterial switch operation & $3(38 \%)$ \\
Left ventricular outflow obstruction repair & $1(13 \%)$ \\
Pulmonary artery banding & $1(13 \%)$ \\
Thoracotomy & 54 \\
Pulmonary artery banding & $4(7 \%)$ \\
\hline
\end{tabular}

Current aortic arch dimensions. Measurements of proximal and distal transverse aortic arch diameter on echocardiogram were obtained in 60 and 61 of 62 patients, respectively. Of the 60 patients with a measurement of proximal transverse arch diameter, $3(5 \%)$ had a $\mathrm{z}$ score $<-2$ and all 3 patients had resting hypertension and abnormal ambulatory blood pressure. Only 1 of the 61 patients $(2 \%)$ with a distal transverse arch diameter measurement had a $\mathrm{z}$ score $<-2$ and had abnormal ambulatory blood pressure and resting hypertension. A measurement of isthmus diameter was possible in 57 patients and $3(5 \%)$ had a $\mathrm{z}$ score $<-2$. All 3 patients had abnormal ambulatory blood pressure $(P=.009)$. In the majority of patients, the flow acceleration observed in the descending aorta was not the result of a discrete stenosis. The mean aortic arch $\mathrm{z}$ score of the proximal transverse arch (60 patients), distal transverse arch (61 patients), and isthmus (57 patients) was $-0.13 \pm 1.38,-0.29 \pm 1.11$, and $-0.18 \pm$ 1.38 , respectively.

\section{Determinants of Hypertension}

All parameters were tested to determine their association with the finding of hypertension at follow-up (Table 4). The presence of associated cardiac anomalies or noncardiac syndromes was not associated with a higher risk of developing hypertension. Smaller aortic arch dimensions at the level of the proximal transverse arch and the isthmus, and higher echocardiographic gradients measured in the descending aorta were associated with abnormal ambulatory blood pressure.

Surgical repair technique. Thirty-four of the 54 patients $(63 \%)$ who underwent coarctation repair via thoracotomy developed abnormal ambulatory blood pressure compared with only 2 of the 6 patients $(33 \%)$ who had an end-toside repair via sternotomy $(P=.11$; Table 3$)$. All but 1 of the 17 patients $(94 \%)$ who had extended end-to-end anastomosis repair via thoracotomy had abnormal ambulatory blood pressure.

TABLE 3. Prevalence of hypertension by resting and 24-hour ambulatory blood pressure for different surgical techniques and for patients with and without reobstruction of the aortic arch

\begin{tabular}{|c|c|c|c|c|c|c|}
\hline \multirow[b]{2}{*}{ Variable } & \multicolumn{3}{|c|}{ Resting BP } & \multicolumn{3}{|c|}{ Ambulatory BP } \\
\hline & Normal + pre-HT & HT & Total & Normal & Abnormal & Total \\
\hline \multicolumn{7}{|l|}{ Technique } \\
\hline Sternotomy & $4(50 \%)$ & $4(50 \%)$ & 8 & $5(63 \%)$ & $3(37 \%)$ & 8 \\
\hline ESA & $3(50 \%)$ & $3(50 \%)$ & 6 & $4(67 \%)$ & $2(33 \%)$ & 6 \\
\hline Patch repair & $1(50 \%)$ & $1(50 \%)$ & 2 & $1(50 \%)$ & $1(50 \%)$ & 2 \\
\hline Thoracotomy & $41(76 \%)$ & $13(24 \%)$ & 54 & $20(37 \%)$ & $34(63 \%)$ & 54 \\
\hline ESA & $3(100 \%)$ & $0(0 \%)$ & 3 & $1(33 \%)$ & $2(67 \%)$ & 3 \\
\hline EEEA & $11(65 \%)$ & $6(35 \%)$ & 17 & $1(6 \%)$ & $16(94 \%)$ & 17 \\
\hline EEA & $2(50 \%)$ & $2(50 \%)$ & 4 & $1(25 \%)$ & $3(75 \%)$ & 4 \\
\hline SFA & $22(82 \%)$ & $5(18 \%)$ & 27 & $14(52 \%)$ & $13(48 \%)$ & 27 \\
\hline Patch repair & $1(100 \%)$ & $0(0 \%)$ & 1 & $1(100 \%)$ & $0(0 \%)$ & 1 \\
\hline Miscellaneous & $2(100 \%)$ & $0(0 \%)$ & 2 & $2(100 \%)$ & $0(0 \%)$ & 2 \\
\hline Total & $45(73 \%)$ & $17(27 \%)$ & 62 & $25(40 \%)$ & $37(60 \%)$ & 62 \\
\hline \multicolumn{7}{|l|}{ Reobstruction } \\
\hline Yes & $11(55 \%)$ & $9(45 \%)$ & 20 & $2(10 \%)$ & $18(90 \%)$ & 20 \\
\hline No & $33(80 \%)$ & $8(20 \%)$ & 41 & $22(54 \%)$ & $19(46 \%)$ & 41 \\
\hline Total & $44(72 \%)$ & $17(28 \%)$ & 61 & $24(39 \%)$ & $37(61 \%)$ & 61 \\
\hline
\end{tabular}

$B P$, Blood pressure; $H T$, hypertension; $E S A$, end-to-side anastomosis; $E E E A$, extended end-to-end anastomosis; $E E A$, end-to-end anastomosis; $S F A$, subclavian flap aortoplasty. 
TABLE 4. Association of clinical and echocardiographic variables with hypertension according to resting and 24-hour ambulatory blood pressure

\begin{tabular}{|c|c|c|c|c|c|c|}
\hline \multirow[b]{2}{*}{$\begin{array}{c}\text { Variables ( } n=62 \text { unless stated } \\
\text { otherwise) }\end{array}$} & \multicolumn{2}{|c|}{ Resting BP } & \multicolumn{2}{|c|}{ Ambulatory BP } & \multicolumn{2}{|c|}{$P$ Value } \\
\hline & Normal + pre-HT & HT & Normal & Abnormal & $\begin{array}{c}\text { Resting HT/ } \\
\text { normal + pre-HT }\end{array}$ & $\begin{array}{c}\text { Abnormal ABP/ } \\
\text { normal ABP }\end{array}$ \\
\hline \multicolumn{7}{|l|}{ General } \\
\hline Age, y & $18.4 \pm 4.8$ & $17.6 \pm 5.6$ & $20.2 \pm 4.1$ & $16.9 \pm 5.1$ & .53 & .01 \\
\hline Age at surgery, $y$ & $0.25 \pm 0.71$ & $0.43 \pm 1.22$ & $0.22 \pm 0.46$ & $0.35 \pm 1.07$ & .46 & .55 \\
\hline Birth weight, $\mathrm{kg}(\mathrm{n}=44)$ & $3.21 \pm 0.56$ & $3.43 \pm 0.59$ & $3.07 \pm 0.65$ & $3.42 \pm 0.46$ & .23 & .04 \\
\hline \multicolumn{7}{|l|}{ M-mode } \\
\hline $\mathrm{FS}, \%(\mathrm{n}=60)$ & $39.2 \pm 9.9$ & $42.2 \pm 8.1$ & $40.5 \pm 12.1$ & $39.8 \pm 7.6$ & .27 & .79 \\
\hline LV mass, $g(n=60)$ & $154.6 \pm 60.3$ & $154.2 \pm 60.3$ & $162.6 \pm 57.0$ & $149.5 \pm 61.7$ & .98 & .41 \\
\hline LV mass index, $\mathrm{g} / \mathrm{m}^{2.7}(\mathrm{n}=60)$ & $40.5 \pm 12.2$ & $38.5 \pm 9.9$ & $41.4 \pm 12.7$ & $39.0 \pm 10.9$ & .54 & .44 \\
\hline \multicolumn{7}{|l|}{ Aortic diameter z scores } \\
\hline Ascending aorta $(\mathrm{n}=56)$ & $1.23 \pm 1.83$ & $0.62 \pm 1.95$ & $1.38 \pm 2.10$ & $0.87 \pm 1.69$ & .28 & .31 \\
\hline PTA $(n=60)$ & $0.12 \pm 1.41$ & $-0.76 \pm 1.11$ & $0.50 \pm 1.60$ & $-0.55 \pm 1.04$ & .03 & .003 \\
\hline Distal transverse $\operatorname{arch}(n=61)$ & $-0.22 \pm 1.20$ & $-0.47 \pm 0.85$ & $-0.07 \pm 1.10$ & $-0.43 \pm 1.11$ & .42 & .21 \\
\hline Isthmus $(\mathrm{n}=57)$ & $-0.20 \pm 1.52$ & $-0.13 \pm 0.97$ & $0.37 \pm 1.20$ & $-0.58 \pm 1.38$ & .87 & .009 \\
\hline Descending aorta $(\mathrm{n}=57)$ & $0.36 \pm 1.46$ & $-0.17 \pm 1.41$ & $0.69 \pm 1.45$ & $-0.14 \pm 1.4$ & .22 & .03 \\
\hline \multicolumn{7}{|l|}{ Maximum velocity $(\mathrm{m} / \mathrm{s})$} \\
\hline Ascending aorta $(\mathrm{n}=61)$ & $1.59 \pm 0.49$ & $1.69 \pm 0.46$ & $1.53 \pm 0.53$ & $1.67 \pm 0.45$ & .43 & .28 \\
\hline Descending aorta $(\mathrm{n}=61)$ & $2.18 \pm 0.55$ & $2.59 \pm 0.46$ & $2.07 \pm 0.34$ & $2.44 \pm 0.61$ & .01 & .009 \\
\hline
\end{tabular}

Residual obstruction. The prevalence of resting hypertension and of abnormal 24-blood pressure monitoring was higher in patients with residual arch obstruction (Table 3). There was a close correlation between the mean 24-hour systolic blood pressure and the echocardiographic gradient measured in the descending aorta $(P=.009$; Figure 2$)$.

\section{Left Ventricular Hypertrophy}

A calculation of left ventricular mass was obtained in 60 of 62 patients $(97 \%)$. Nineteen of these 60 patients $(32 \%)$ had indexed values of left ventricular mass fitting the criteria of left ventricular hypertrophy. A similar proportion of patients with resting hypertension $(5 / 17,29 \%)$ or abnormal ambulatory blood pressure $(12 / 37,32 \%)$ had left ventricular hypertrophy. There was no evidence of an association between left ventricular hypertrophy and either resting hypertension (odds ratio $=0.86,95 \% \mathrm{CI}=0.3-2.9, P=.81$ ) or abnormal ambulatory blood pressure (odds ratio $=1.1$, $95 \% \mathrm{CI}=0.4-3.4, P=.87$ ).

\section{DISCUSSION}

It is likely that our community of surgeons and cardiologists underestimate the prevalence of hypertension after coarctation repair. The prevalence quoted by many retrospective studies $^{1-3}$ extracting information from patient files have been reassuringly low and, as a consequence, it is likely that patients and families are not appropriately aware of the risks of developing hypertension at a young age after coarctation repair, and of its lethal consequences. Twenty-four-hour blood pressure monitoring is the gold standard for detecting hypertension. ${ }^{8}$ There seems to be only 2 studies that attempted to circumscribe the prevalence of hypertension after coarctation repair with this modality. ${ }^{4,5}$ Both point to a prevalence that may be close to $50 \%$ in young adults. O'Sullivan and colleagues ${ }^{4}$ established a prevalence of $30 \% 10$ years after repair, but it is possible that the prevalence of hypertension will increase with age. The other study, by de Divitiis and colleagues, ${ }^{5}$ described a prevalence of $50 \%$, but only 72 patients, one fifth of their targeted population, were screened. The true prevalence of hypertension after coarctation repair is, therefore, still uncertain, especially in patients presenting with hypoplastic arches at the time of the repair.

Residual aortic arch obstruction has been identified to be 1 of the predominant factors leading to hypertension. ${ }^{6} \mathrm{We}$ have demonstrated recently that the hypoplastic segments

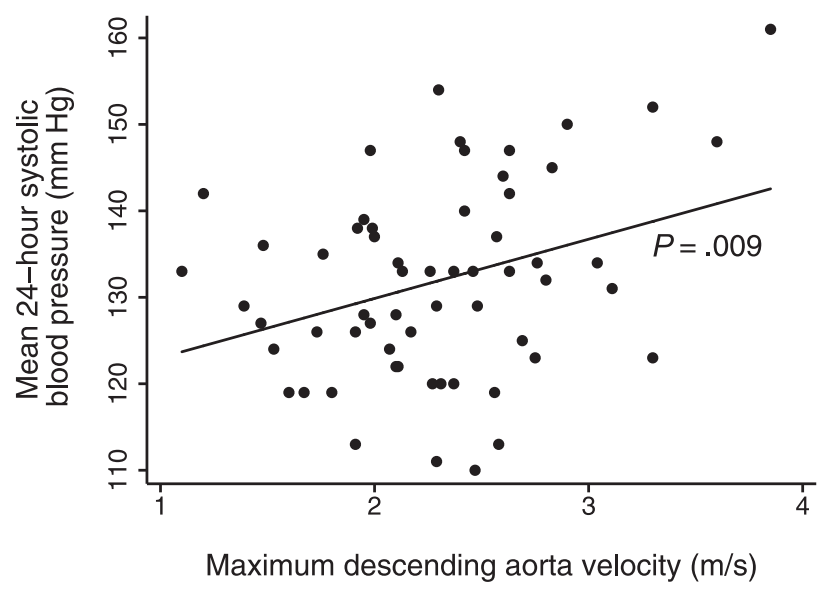

FIGURE 2. Mean 24-hour systolic blood pressure versus maximum descending aorta velocity. 
of proximal transverse arch left untouched by the repair often remain small, and we were suspicious that repair through a thoracotomy of patients with coarctation and hypoplastic arch would generate a high proportion of hypertensive patients. ${ }^{12}$ In our current study, an alarming rate of $60 \%$ of the patients who were quoted to have a hypoplastic arch at the time of the coarctation repair were shown to be hypertensive at a median of 17 years after repair. This prevalence was much higher if the patients underwent a procedure via a thoracotomy than an end-to-side repair via a sternotomy. Casual blood pressure measurements grossly underestimated the prevalence of hypertension as detected by 24 -hour blood pressure monitoring with a sensitivity of only $41 \%$.

\section{Limitations}

There are 3 obvious limitations to this study. First, the selection of the patients who had a hypoplastic arch at the time of the repair may seem vague because it relies on the subjective appreciation of the surgeons, cardiologists, and echocardiography technicians taking care of the patients. It is, however, impossible to select patients on strict echocardiographic criteria if they were operated on 2 decades ago. The concept of hypoplastic arch itself is poorly defined. It has been based previously on the ratio between segments of the arch often undefined and the descending or the ascending aorta. ${ }^{9-11,20}$ In the current and previous studies, we have found a great variability in the size of the descending aorta and its body surface area indexed values, making the ratio between different segments of aorta unreliable. ${ }^{12}$ Like others, we adopted $\mathrm{z}$ score values, but the definition of hypoplasia has not yet been defined on their basis. ${ }^{11}$ The cutoff sizes to define hypoplastic arches in the previous historical studies were based on either arbitrary decisions or on the variation from normality defined on autopsy specimens. ${ }^{21}$ Ideally, hypoplasia of the aortic arch should be defined on the basis of adverse late outcomes, but these have not yet been defined. It is likely, however, that in our study, applying more stringent criteria of hypoplastic arches would have resulted in an even greater prevalence of hypertension.

Second, the delineation of arch obstruction by echocardiography can be subjected to criticism because of the difficulty in acquiring adequate visualization of the descending aorta in adult patients. The design of the study did not allow us to determine whether the flow acceleration observed in the descending aorta appeared progressively or whether it was already present immediately after the initial procedure. We found the clinical detection of arch obstruction by blood pressure measurements in the arm and leg highly unpredictable and we do not have the facilities that allow for the screening of large populations by magnetic resonance imaging.

Finally, it could be argued that 24-hour blood pressure monitoring will not have a clinical impact in all these patients. The knowledge that hypertension in young adults after coarctation repair results in mortality in the 3 decades following the repair has been ascertained on the basis of only 1 historical study dating from the end of the $1980 \mathrm{~s}$ and has not been corroborated in more recent times. ${ }^{3}$ This suspicion may be reinforced by the fact that we did not observe any differences between the prevalence of left ventricular hypertrophy in normotensive and hypertensive patients. It is still unclear at this stage whether we should be reassured by this equal prevalence or whether we should be concerned that even one third of the normotensive patients show signs of left ventricular hypertrophy. There is now ample evidence that hypertension defined by 24-hour blood pressure monitoring correlates more closely to endorgan damage in adults and children than hypertension defined by casual resting blood pressure measurements. ${ }^{7,22,23}$ It would be surprising if the patients that we found to be hypertensive on the basis of 24-hour blood pressure monitoring did not experience adverse outcomes, even if the timeline at which end-organ damage occurs is not yet established in this population.

\section{Determinants of Hypertension}

The existence of residual aortic arch obstruction was the factor that correlated most closely to the existence of hypertension, and the current study emphasizes once again the absolute necessity for a complete relief of any arch obstruction. The measurements of the arch seem to point to a generalized hypoplasia of the transverse arch being the cause of the obstruction rather than any focal stenosis.

Our center has promoted the technique of end-to-side repair of the aortic arch for interrupted and hypoplastic aortic arch since the mid 1980s. We have been able to demonstrate that the late prevalence of hypertension was very low after this procedure when performed for interrupted aortic arch repair. $^{24}$ The number of patients who had undergone this technique in the current study did not allow us to draw any valid conclusions yet, but we found the trend of these patients being less susceptible to experiencing hypertension to be encouraging. At this stage, one cannot exclude that the hypertension observed in our patients was the result of vascular changes induced early in life and are not related to the size of the aortic arch after surgery. ${ }^{25}$ Although residual obstruction is not the only contributing factor to late hypertension in this population, it is likely to play a predominant role and all efforts should be made to ensure an adequate size of the entire aortic arch in the long term.

In conclusion, patients with a hypoplastic arch operated on with a thoracotomy have an alarming prevalence of hypertension. Regular follow-up with 24-hour ambulatory blood pressure monitoring should be warranted after coarctation repair, especially in patients who had a smaller aortic arch at the time of the initial operation. 


\section{References}

1. Seirafi PA, Warner KG, Geggel RL, Payne DD, Cleveland RJ. Repair of coarctation of the aorta during infancy minimizes the risk of late hypertension. Ann Thorac Surg. 1998;66:1378-82.

2. Clarkson PM, Nicholson MR, Barratt-Boyes BG, Neutze JM, Whitlock RM. Results after repair of coarctation of the aorta beyond infancy: a 10 to 28 year follow-up with particular reference to late systemic hypertension. Am J Cardiol. 1983;51:1481-8

3. Cohen M, Fuster V, Steele PM, Driscoll D, McGoon DC. Coarctation of the aorta. Long-term follow-up and prediction of outcome after surgical correction. $\mathrm{Circu}$ lation. 1989;80:840-5.

4. O'Sullivan JJ, Derrick G, Darnell R. Prevalence of hypertension in children after early repair of coarctation of the aorta: a cohort study using casual and 24 hour blood pressure measurement. Heart. 2002;88:163-6.

5. de Divitiis M, Pilla C, Kattenhorn M, Donald A, Zadinello M, Wallace S, et al. Ambulatory blood pressure, left ventricular mass, and conduit artery function late after successful repair of coarctation of the aorta. J Am Coll Cardiol. 2003;41:2259-65.

6. Hager A, Kanz S, Kaemmerer H, Schreiber C, Hess J. Coarctation long-term assessment (COALA): significance of arterial hypertension in a cohort of 404 patients up to 27 years after surgical repair of isolated coarctation of the aorta, even in the absence of restenosis and prosthetic material. J Thorac Cardiovasc Surg. 2007; 134:738-45.

7. Palatini P, Mormino P, Santonastaso M, Mos L, Pessina AC. Ambulatory blood pressure predicts end-organ damage only in subjects with reproducible recordings. HARVEST Study Investigators. Hypertension and Ambulatory Recording Venetia Study. J Hypertens. 1999;17:465-73.

8. Urbina E, Alpert B, Flynn J, Hayman L, Harshfield GA, Jacobson M, et al. Ambulatory blood pressure monitoring in children and adolescents: recommendations for standard assessment: a scientific statement from the American Heart Association Atherosclerosis, Hypertension, and Obesity in Youth Committee of the Council on Cardiovascular Disease in the Young and the Council for High Blood Pressure Research. Hypertension. 2008;52:433-51.

9. Jahangiri M, Shinebourne EA, Zurakowski D, Rigby ML, Redington AN, Lincoln C. Subclavian flap angioplasty: does the arch look after itself? J Thorac Cardiovasc Surg. 2000;120:224-9.

10. Myers JL, McConnell BA, Waldhausen JA. Coarctation of the aorta in infants: does the aortic arch grow after repair? Ann Thorac Surg. 1992;54:869-74; Discussion, 74-5.

11. Brouwer MH, Cromme-Dijkhuis AH, Ebels T, Eijgelaar A. Growth of the hypoplastic aortic arch after simple coarctation resection and end-to-end anastomosis. J Thorac Cardiovasc Surg. 1992;104:426-33.

12. Liu JY, Kowalski R, Jones B, Konstantinov IE, Cheung MM, Donath S, et al. Moderately hypoplastic arches: do they reliably grow into adulthood after conventional coarctation repair? Interact Cardiovasc Thorac Surg. 2010;10: 582-6.

13. Pettersen MD, Du W, Skeens ME, Humes RA. Regression equations for calculation of $\mathrm{z}$ scores of cardiac structures in a large cohort of healthy infants, children, and adolescents: an echocardiographic study. J Am Soc Echocardiogr. 2008;21: 922-34.

14. Lang RM, Bierig M, Devereux RB, Flachskampf FA, Foster E, Pellikka PA, et al. Recommendations for chamber quantification: a report from the American Society of Echocardiography's Guidelines and Standards Committee and the Chamber Quantification Writing Group, developed in conjunction with the European Association of Echocardiography, a brand of the European Society of Cardiology. J Am Soc Echocardiogr. 2005;18:1440-63.

15. Daniels SR, Kimball TR, Morrison JA, Khoury P, Meyer RA. Indexing left ventricular mass to account for differences in body size in children and adolescents without cardiovascular disease. Am J Cardiol. 1995;76:699-701.

16. de Simone G, Daniels SR, Devereux RB, Meyer RA, Roman MJ, de Divitiis O, et al. Left ventricular mass and body size in normotensive children and adults: assessment of allometric relations and impact of overweight. J Am Coll Cardiol. 1992;20(5):1251-60.

17. National High Blood Pressure Education Program Working Group on High Blood Pressure in Children and Adolescents. The fourth report on the diagnosis, evaluation, and treatment of high blood pressure in children and adolescents. Pediatrics. 2004; 114:555-76.

18. Chobanian AV, Bakris GL, Black HR, Cushman WC, Green LA, Izzo JL Jr, et al. The seventh report of the Joint National Committee on Prevention, Detection, Evaluation, and Treatment of High Blood Pressure: the JNC 7 report. JAMA. 2003;289:2560-72.
19. Pickering TG, Hall JE, Appel LJ, Falkner BE, Graves J, Hill MN, et al. Recommendations for blood pressure measurement in humans and experimental animals: part 1: blood pressure measurement in humans: a statement for professionals from the Subcommittee of Professional and Public Education of the American Heart Association Council on High Blood Pressure Research. Hypertension. 2005;45:142-61.

20. Vouhe PR, Trinquet F, Lecompte Y, Vernant F, Roux PM, Touati G, et al. Aortic coarctation with hypoplastic aortic arch: results of extended end-to-end aortic arch anastomosis. J Thorac Cardiovasc Surg. 1988;96:557-63.

21. Moulaert AJ, Bruins CC, Oppenheimer-Dekker A. Anomalies of the aortic arch and ventricular septal defects. Circulation. 1976;53:1011-5.

22. Verdecchia P, Clement D, Fagard R, Palatini P, Parati G. Blood Pressure Monitoring. Task Force III: target-organ damage, morbidity and mortality. Blood Press Monit. 1999;4:303-17.

23. Mancia G, Zanchetti A, Agabiti-Rosei E, Benemio G, De Cesaris R, Fogari R, et al. Ambulatory blood pressure is superior to clinic blood pressure in predicting treatment-induced regression of left ventricular hypertrophy. SAMPLE study group: Study on Ambulatory Monitoring of Blood Pressure and Lisinopril Evaluation. Circulation. 1997;95:1464-70.

24. Hussein A, Iyengar AJ, Jones B, Donath SM, Konstantinov IE, Grigg LE, et al. Twenty-three years of single-stage end-to-side anastomosis repair of interrupted aortic arches. J Thorac Cardiovasc Surg. 2010;139:942-7. 49; Discussion, 48.

25. de Divitiis M, Pilla C, Kattenhorn M, Zadinello M, Donald A, Leeson P, et al. Vascular dysfunction after repair of coarctation of the aorta: impact of early surgery. Circulation. 2001;104:I165-70.

\section{Discussion}

Dr J. William Gaynor (Philadelphia, Pa). I'd like to congratulate Ms Lee and her coauthors on an excellent study, a wonderful presentation, and thank them for sharing their manuscript with me.

This is a very timely topic. Obviously, as early outcomes for congenital heart defects improve, follow-up with the later outcomes becomes critically important. And this demonstrates that even simple lesions, such as coarctation, which many people think are fixed - in some studies none of these patients are even followed by their cardiologist—have an alarming incidence of problems. I have a couple of questions concerning this.

First, you found by echo a significant incidence of reobstruction, and in the manuscript this is attributed to the hypoplastic arches. Can you tell me from the echoes where was the level of obstruction? Was it in the proximal arch or was it at the coarctation site itself?

Dr d'Udekem. There were 20 patients who had reobstruction on echo. Their obstruction was defined on the basis of a flow acceleration into the descending aorta, and the gradient was superior to $25 \mathrm{~mm} \mathrm{Hg}$. They could not determine by the flow acceleration the site of the obstruction. However, if you look at the measurements of the aortic arch on echocardiogram, there were 5 patients who had a segment of transverse arch that had a $\mathrm{z}$ score of $<-2$ : 1 patient in the proximal arch, 2 patients in the distal arch, and 2 patients in the isthmus. And, interestingly, if you compare this size with the descending aorta, they would be all considered normal. Interestingly, there was a significant difference in the size of the descending aorta between the patients with hypertension and those without. I cannot explain that, but the hypertensive ones have a smaller descending aorta.

When you look at the absolute number, the transverse arch seems to be tapering down so that the size of the proximal arch is between $1 \mathrm{~cm}$ and $2 \mathrm{~cm}$, but more around the $1.5-\mathrm{cm}$ mark, and it goes a little bit smaller onto the distal transverse arch and, again, a touch smaller on the isthmus. So it doesn't fit the criteria for obstruction strictly, but it seems to be tapering down, which 
makes me think that maybe the definition of obstruction is not really good, because maybe having just a slightly smaller aorta is enough to generate hypertension.

Dr Gaynor. And sort of along those lines, did you look at the postoperative echoes? Do you know that there was adequate relief of the obstruction at the time of the initial repair? Are we seeing recurrent obstruction in these patients or residual obstruction? Because if you still have residual obstruction, it may affect the flow in the arch.

Dr d'Udekem. We don't have these results. But you have to remember that only half of those who were hypertensive in the long term had reobstruction. So the way we define obstruction is not able to identify the patients who develop hypertension in the long term. And we suspect that having a small transverse arch is a factor that promotes the genesis of hypertension. It may not be the only one, as has been noted in the literature.

Dr Gaynor. I also think it's important to look at the growth characteristics. I mean, you state that the proximal arch didn't grow; however, the average $\mathrm{z}$ score was -2.43 before surgery, and at the time of your last follow-up only 3 patients had a $\mathrm{z}$ score $<-2$. By definition, those are within the normal range. So there was growth.

And along those lines, you don't discuss it really here or in the manuscript, you had a sizable subgroup of patients who had subclavian flap aortoplasties. With that repair, nothing is done to address the arch. Yet that did not appear to come out in your analysis as a risk factor for reobstruction. So there is evidence from some studies that the proximal arch may grow after a subclavian flap. So I don't know how to put these pieces of information together.

I'm concerned that it may not be obstruction. There was only 1 patient with a blood pressure gradient, and the degree of obstruction is fairly mild. I'm not sure that we can attribute the hypertension to either the small arch or reobstruction. I'm more concerned this is an intrinsic abnormality of the aorta. We know that the endothelial function in the precoarctation bed remains abnormal even after a successful neonatal repair. And, more important, the aortic wall is very noncompliant. So this may not have anything to do with reobstruction or a small arch. It may just be an intrinsic characteristic of the aorta, which would explain why you don't find a relationship between the degree of obstruction and the degree of hypertension.

Dr d'Udekem. I think the questions of how much the size, the physical size of the arch, and how much these neurohumoral factors account for the development of hypertension remains open. It's difficult to sort out these issues and we keep working on this topic.

We demonstrated in a previous publication that the statement that the proximal transverse arch would grow if you restored normal antegrade flow after coarctation repair does not always stand true, but not to the point that it would give you a proximal transverse arch with a $\mathrm{z}$ score of -3 or -4 . If you look at the data, the arches do grow in some instance, but not reliably, not all of them. And that's why we were still doing subclavian flap repair at the time.

Dr Gaynor. But in the table in your paper, the incidence of hypertension at the subclavian flap was less than after the extended end-to-end repair and basically the same as for your overall sternotomy group. So I think it's important to realize that in some patients you didn't address the arch and those did not have a higher incidence.

And we have seen anecdotally, we see these kids who have had coarctation repairs and then come in with some mild obstruction. They always tend to be athletes who get very hypertensive during exercise. We relieve the obstruction either with a balloon or surgery. They still have hypertension after exercise, suggesting, again, it's intrinsic aortic wall, not the obstruction.

Dr d'Udekem. There are 2 things. When you look at the results from 24-hour blood pressure monitoring, we fit them in the recommended criteria. So if they're hypertensive, they're hypertensive. The criteria are very clear.

But the pressure is not always dramatically high. So a mean blood pressure of $135 \mathrm{~mm} \mathrm{Hg}$ would bring you into a category of hypertensive patient. I don't know personally how relevant that is. The other point is, we've reviewed 305 patients who were not screened with 24-hour blood pressure monitoring. What we've seen is that, with casual blood pressure measurements, the patients who had reintervention were no longer hypertensive in the long term.

Dr Gaynor. I don't think we know. But all I'm saying is I don't think the data fully prove or support your hypothesis that the hypertension is the result of failure of growth of the proximal arch. Because we don't know where the level of reobstruction is, there is not a good correlation of reobstruction with the hypertension.

And even your ambulatory pressures did not correlate with left ventricular hypertrophy, so we don't know what the significance of the hypertension is, which suggests this is relatively mild. And, again, I'm concerned we may be going down sort of the wrong path of looking at the anatomic characteristics of the arch that may just be intrinsic to these patients and there may be other therapies that are necessary.

Dr John Foker (Minneapolis, Minn). I would like to reinforce the points that Bill has just made. If you have a very tight coarctation, lower body flow is provided with the ductus, arch flow will be reduced, and the transverse arch is going to be small. We have begun looking at our $>300$ rotated subclavian flap repairs, many of them in patients who are $<1$ month of age. Although our review is not complete, the reinterventions-by balloon dilation, usually-were for problems around the coarctation site. We are finding the arch grew reliably when increased flow through it was established.

Dr d'Udekem. I commend you for your excellent results, and I apologize for what I will say. I know that in the literature the people say that the aortic arch grew, but you have to be realistic. And I invite you to review the literature on the topic; it's really appalling. I mean, it's possible that the arch really grows, but please give me data. The only reports that are published specify a ratio between the transverse arch and the descending aorta, and we found that to be unreliable when you look carefully at the patients because there is enormous variability in the size of the aorta. There is 1 paper in the literature that has looked at the $\mathrm{z}$ score of the transverse arch, and that's only a single paper, and it does not describe at which level of the proximal or the distal transverse arch the measurements were taken. So I'm ready to believe all of you that the proximal transverse arch does grow after coarctation repair, but please give me the evidence. I'm sorry. 
Dr Foker. You do not have to apologize; good data are necessary and I provided none. We believe that with a very tight coarctation, there is no reason the transverse arch should be any larger than the subclavian artery. So far, in the review of our patients, relief of obstruction produced catch-up growth, indicating the hypoplasia is flow related rather than intrinsic. But, careful measurements are necessary. Nevertheless, as the preceding discussion brought out, there are other important factors including the nature of the vessel walls that will affect the outcome.

Dr Emile Bacha (New York, NY). But on the opposite side there are also tight coarctations with normal-size aortic arches, so it's not always the case that if you have a tight coarctation you get a hypoplastic arch.

Dr Foker. I'm overstating it to make the point. But vessels grow with flow. I mean, they really do.

Dr Bacha. I think 1 nice point that I learned from this study is that the 24-hour monitoring will detect some patients who don't know they're hypertensive, which is something that I really never realized.

Dr Joseph J. Amato (Chicago, Ill). I have just completed an extensive review on coarctation of the aorta. To begin with, first of all, the Waldhausen procedure has been shown to have tremendous amount of residual coarctations. A recent chapter in Pediatric Cardiac Surgery by Dr Backer shows the results of 8 institutions using this method to have as high as $23 \%$ to $42 \%$ of recoarctation. Also, the possibility of left arm ischemia, and loss of length and function of the left arm are possible. I really believe that this operation should not be used.

The second comment is to ask you to define the types of end-toend or extended surgical methods that you chose. Was this the
Amato extended end-to-end or the Elliott or Zannini types? With these later types, you can extend the anastomosis quite a way across the arch.

Also, there are measurements of the size of the aortic arch. These are usually divided into 3 segments and can be defined as hypoplastic either when less than the size of the innominate artery in millimeters or less than the body weight in kilograms plus $1 \mathrm{~mm}$.

I agree that looking at preoperative hypertension might have been impossible because these were infants who did not have time to develop hypertension. Thank you.

Dr d'Udekem. The majority of them were neonates. And it's old records.

Dr Amato. What about the size of the left ventricle? Was their left ventricular hypertrophy massive, severe, small?

Dr d'Udekem. They were neonates and they were operated more than 18 years ago. It's very difficult to get these data.

Dr Stephen Langley (Portland, Ore). Melissa, congratulations. It's very difficult as a medical student to come and present at this meeting. In fact, it can very difficult even if you're not a medical student to come and present here; so, congratulations.

One question for Yves: Has this study altered your practice? And if so, how? And what are your current criteria for doing an arch repair or a coarctation repair via a median sternotomy?

Dr d'Udekem. I'm a bit scared now, but thank you for asking the question. Today in Melbourne, we look at the proximal transverse arch because we've shown that the distal transverse arch can be solved by an extended end-to-end repair and there is no question about that. But if today you're presenting in Melbourne with a proximal transverse $\operatorname{arch~} \mathrm{z}$ score that is $<-2$, you would have an operation from the front and an end-to-side repair. 